\title{
'N ONDERSOEK NA TAALPROBLEME BY LEERGESTREMDE KINDERS.
}

\author{
ELIZE DE KOKER, M. (LOG.) (PRET.) \\ Department Speech Pathology and Audiology, University of the Witwatersrand, \\ Johannesburg
}

\section{OPSOMMING}

Hierdie studie ondersoek met behulp van die Toets vir Mondelinge Taalproduksie (TMT) (Vorster 1980), die taalvermoëns van 'n groep van 30 leergestremde kinders. Resultate het getoon dat, wat betref mondelinge taalproduksie, die eksperimentele leergestremde groep betekenisvol swakker as die normgroep presteer. Die voorkoms en aard van betrokke taalprobleme, asook die nut van die TMT vir gebruik by leergestremde kinders, word bespreek.

\section{SUMMARY}

The study examined the language abilities of a group of 30 learning-disabled children using the "Toets vir Mondelingse Taalproduksie" (TMT) (Vorster, 1980). Results revealed a significant difference between the scores of the experimental group and the norms of the test. The evidence and nature of proven oral language difficulties were discussed as well as the use of the TMT with learning disabled children.

Die wetenskaplike vakgebied van "leergestremdheid" het met die verskyning van die Murray-verslag in 1969 sy amptelike beslag in Suid-Afrika gekry. Hierdie vakgebied het sy ontstaan oor 'n lang tydperk gehad vanaf 1800 tot 1940 (Myers en Hammill ${ }^{13}$ ). Hierdie periode word veral gekenmerk deur min of geen empiriese navorsing waar observasies van breinbeseerdes die grondslag van die teoretiese kennis gevorm het.

Met die verloop van tyd het navorsers daarin geslaag om tussen verskillende soorte leerprobleme te onderskei. Uys ${ }^{17}$ byvoorbeeld, noem dat verstandelike vertraging, emosionele versteuring en sintuiglike gebreke reeds in die middel van die twintigste eeu as oorsake van leerprobleme bekend was.

Daar het geleidelik egter 'n nuwe soort leergestremde kind onder die aandag van navorsers gekom, naamlik 'n kind wat nie:

- verstandelik vertraag

- sintuiglik gestremd

- primêr emosioneel versteurd

- of motories gestremd was nie,

maar wat wel skolastiese probleme ondervind het en byvoorbeeld nie leer lees, skryf, praat en reken het nie (Johnson en Myklebust, ${ }^{9}$ ). Soos byna sonder uitsondering die geval in die "gedragswetenskappe" is, het daar letterlik tientalle definisies, diagnostiese en remediëringsmetodes en benaderings tot hierdie kinders ontstaan. Baren ${ }^{2}$ noem dat die verskeidenheid van terme wat vir die probleem ontstaan het tot 
geweldige verwarring aanleiding gegee het. Dit is egter nie slegs die terminologie wat kontroversieel geword het nie, maar die hele studiegebied van leergestremdheid.

Die redes vir die verwarring en kontroversie wat daar heers, lê hoofsaaklik in die volgende faktore opgesluit:

- Die leergestremde kind het eerstens 'n baie gevarieërde en wye simptoombeeld. Kirk en Kirk ${ }^{10}$ noem byvoorbeeld dat gestremde kinders nie altyd in sulke goed gedefinieërde kategorieë met homogene eienskappe tuishoort nie. Navorsers het dus probleme ondervind om dié studiegebied logies en goedgedefinieerd af te baken.

- Tweedens is die leemtes in die kennis ten opsigte van die sentrale senuweestelsel en sy funksionering 'n baie beperkende faktơ in die studiegebied.

- Derdens, en seker die belangrikste faktor wat ongetwyfeld tot die verwarring moes bydra, was daardie baie denkrigtinge en dissiplines wat hulle met dié kinders bemoei, bydraes gelewer, gediagnoseer en behandel het.

Die spektrum van geïnteresseerde persone sluit onder andere die volgende in: sielkundiges, onderwysers, sosiale werkers, medici, spraakterapeute, opvoedkundiges, arbeidsterapeute, neuroloë, pediaters, - mense met verskillende teoretiese agtergronde en uitgangspunte.

Die genoemde verwarring wat daar heers, is ongetwyfeld slegs tot nadeel van die leergestremde kind en daarom moet die oplossing van die verwarring en kontroversie 'n primêre doelstelling word. Dié doelstelling kan onder andere verwesenlik word deur meer en verbeterde empiriese navorsing.

Daar moet dus gepoog word om die leemtes in die huidige korpus van kennis en navorsing in die studiegebied te identifiseer en nader te bestudeer.

\section{PROBLEEMSTELLING}

Slegs een leemte sal vervolgens genoem en bestudeer word naamlik die feit dat die leergestremde kind se taalproblematiek, en dan veral gesproke taal, grootliks in die diagnose en remediëring van die kinders oor die hoof gesien is. (Wiig en Semel, ${ }^{23}$ Hallahan en Kauffman, ${ }^{7}$ ) 'n Bewys vir hierdie stelling is die feit dat Hallahan ${ }^{7}$ drie keer meer artikels in die literatuur vir leergestremdheid ten opsigte van perseptueel - motoriese probleme gevind het, in vergelyking met artikels oor die kinders se moontlike taalprobleme.

Dié perseptueel-motoriese benadering wat tot leerprobleme gevolg word, kan ongetwyfeld weens die pionierswerk van mense soos Strauss en Cruickshank verantwoord word (Myers en Hammill, ${ }^{13}$ )

Wallach en Goldsmith ${ }^{20}$ is egter verder van mening dat hierdie benadering nie slegs weens die bydraes van die pioniers op die gebied gevolg word nie, maar ook omdat professionele persone reeds jare 
lank van mening is dat die kern van die leergestremde kind se probleem die perseptueel-motoriese aantasting is. 'n Rede hiervoor kan wees dat lees-problematiek met 'n baie hoë frekwensie onder leergestremde kinders voorkom en lees as 'n uitsluitlike visuele taak gesien word.

Alhoewel dit nie weg te redeneer is dat perseptuele defekte in samehang met leergestremdhede voorkom nie, is hierdie benadering nie 'n bevredigende oplossing nie.

Baren $^{2}$ sê byvoorbeeld in die verband dat daar geen bewyse is dat perseptuele vermoëns so belangrik vir die leerproses is as wat veronderstel word nie.

Wallach en Goldsmith ${ }^{20}$ haal "ook ter ondersteuning van bogenoemde stelling vyf outeurs aan wat die volgende mening toegedaan is:

. . question the validity of available visual perceptual testing materials and most importantly question the educational usefulness of the concept of perceptual deficit in treating learning disabilities

Kritiek kan ook uitgespreek word teen die engheid van 'n perseptuele benadering. Daar moet onthou word dat daar verskillende vlakke in die leerproses bestaan. Dit is verkeerd om slegs op die hiërargies laer vlakke van die leerproses nl. motoriek en persepsie te konsentreer en prosesse soos simbolisering en konseptualisering op die hoëre vlakke van die leerproses (Myers en Hammill, ${ }^{13}$ Johnson en Myklebust, ${ }^{9}$ ) oor die hoof te sien.

Ter motivering van 'n taalbenadering tot leergestremde kinders kan daar geen eenvoudiger motivering wees as die feit dat taalprobleme wel 'n deel van dié kinders se simptoombeeld vorm nie. Daar word spesifiek van 'n leergestremde kind gepraat as gevolg van die opvoedkundige of skolastiese probleme wat hulle ondervind skolastiese take wat vermoëns soos lees, spel, skryf en reken insluit. Die genoemde vermoëns is almal sekondêre taalvermoëns.

Alhoewel Monroe (Wiig en Semel, ${ }^{23}$ ) reeds in 1932 gevind het dat taal- en leerprobleme dieselfde etiologiese faktore toon, kan daar selfs nog aan die begin van die tagtigerjare gesê word dat navorsing na die aard en voorkoms van die taalprobleme nog byna afwesig is.

Die spraakterapeut, onderwyser of opvoedkundige staan dus in die praktyk dikwels magteloos in hulle hantering van taalprobleme wat opgemerk word, veral omdat daar nie diagnostiese toetse bestaan nie en omdat daar oor die algemeen so min kennis en gevolglik min literatuur in die verband beskikbaar is.

Dit is dus verstaanbaar dat sommige outoriteite wat by léergestremde kinders betrokke is, orale taalprobleme oor die hoof sal sien en op perseptueel-motoriese probleme sal konsentreer.

Deur middel van hierdie projek is daar dus gepoog om die genoemde leemte te vul wat veral by die Afrikaanse leergestremde kind soveel groter is. Daar word ook gehoop dat dit verdere navorsing sal stimuleer en die gebrekkige belangstelling waarvan Wiig en Semel ${ }^{23}$ ) praat, sal ophef. 


\section{EKSPERIMENTELE ONTWERP}

\section{SPESIFIEKE DOELSTELLINGS EN HIPOTESE}

Bewys van orale taalproblematiek

Deur middel van die eksperimentele metode wat vervolgens bespreek sal word, is daar gepoog om te bewys dat leergestremde kinders taalprobleme het. Daar word spesifiek na orale taal gekyk omdat dit die mees waarneembare asook die basiese medium is.

Die motivering hiervoor is as volg: Moran en Byrne ${ }^{11}$ noem dat daar tans steeds beperkte bewyse is dat die leergestremde kind se taal van dié van die normale kind verskil. Vogel ${ }^{18}$ noem die "moontlikheid" dat dislektiese kinders afwykings in orale sintaksis het. Uit bogenoemde drie outeurs se bydraes is dit duidelik dat daar nog min wetenskaplike bewyse bestaan, alhoewel outoriteite spekuleer dat daar wel taalprobleme voorkom.

Bogenoemde beperkte bewyse en min navorsing word ook deur outeurs soos Wiig en Semel ${ }^{22}$, 23 Wiig en Roach $^{21}$ en Hallahan ${ }^{7}$ onderskryf.

Hallahan en Kauffman ${ }^{7}$ is van mening dat die studies so beperk in getal is en dat daar soveel teenstrydighede bestaan, dat verdere navorsing noodsaaklik is.

Daar word spesifiek die hipotese gestel dat leergestremde kinders wel gesproke taalprobleme het.

Voorkoms van taalproblematiek

Daar is ook gepoog om die vookoms van taalprobleme onder die leergestremde bevolking te bepaal.

Die motivering vir bogenoemde is as volg:

As daar bewys kon word dat leergestremde kinders wel taalprobleme het en dat daar 'n relatiewe hoë insidensie is, gee dit soveel meer rede vir 'n betoog dat die kinders se taal meer aandag moet geniet.

Daar is spesifiek ouer kinders, m.a.w. sewe- tot tienjariges in die studie ingesluit. Hierdeur is daar gepoog om uitsluitsel te verkry oor die kontroversie wat daar bestaan met betrekking tot die aanwesigheid, al dan nie van simptome van leergestremdheid by ouer kinders.

Die aard van die taalproblematiek

Daar is derdens deur hierdie eksperiment gepoog om die aard van die taalprobleme te bestudeer.

Die volgende vrae kan byvoorbeeld gevra word:

- Verskil die leergestremde kind se orale taal kwalitatief of kwantitatief van die normale kind s'n?

- Is daar 'n aparte diagnostiese kategorie waarin die leergestremde bevolking ten opsigte van taalvermoëns pas?

- Wat is die verhouding of onderlinge verband tussen die taal en leerprobleme? 
Evaluering van die Toets vir Mondelinge Taalproduksie (TMT)

Aangesien die toets tans die enigste normatiewe data ten opsigte van sekere aspekte van die ouer Afrikaanse kind se taalvermoë verskaf is dit belangrik dat die waarde van die toets se gebruik by leergestremde kinders bepaal sou word.

\section{SELEKSIE VAN PROEFPERSONE}

Kriteria vir seleksie

In 'n poging om die orale taal van leergestremde kinders met die van normales te vergelyk, is daar van 'n eksperimentele, sowel as kontrole groep (EG en $\mathrm{KG}$ ) gebruik gemaak.

\section{Kontrole groep}

Die KG is die verteenwoordigende steekproef waarop die norms van die TMT gestandardiseer is.

\section{Eksperimentele groep}

Die volgende kriteria is aan die groep gestel:

(i) Kinders met 'n leergestremdheid moes geselekteer word. Omdat daar soveel moontlike interpretasies van dié term bestaan, word die volgende definisie as kriterium gebruik: Die kinders mag nie

- opvallende fisiese of sintuiglike gebreke gehad het nie

- ernstig emosioneel versteur gewees het nie

- gemanifesteerde epilepsie of serebrale verlamming ondervind het nie

- daar moes wel sagte neurologiese tekens teenwoordig gewees het

(ii) Omdat ' $n$ ondergemiddelde intelligensie taaltoetse nadelig beïnvloed, is daar vereis dat proefpersone (pp) 'n gemiddelde intelligensie sou hê (m.a.w. 100+)

(iii) Skoolgaande kinders is geselekteer omdat intelligensie syfers by hulle meer betroubaar is. Leergestremdheid is by hulle ook reeds geïdentifiseer en daar kon so ook afleidings gemaak word t.o.v. die aanwesigheid van taalproblematiek tydens stadia waar dit nie meer verwag word nie $\left(\right.$ Schain $\left.^{16}\right)$

.(iv) Dertig proefpersone is geselekteer om statisties betekenisvolle resultate te kon verkry

(v) Emosionele onstabiliteit, sosio-ekonomiese status, sowel as geslag is as moontlike beïnvloedende faktore in ag geneem. Eersgenoemde twee faktore is deur ewekansige steekproeftrekking geassimileer. Omdat leergestremdheid baie meer by seuns as dogters aanwesig is, is daar besluit op 'n ewekansige steekproef. Daar sal dus noodwendig meer'seuns as dogters in die steekproef wees wat 'n getroue weergawe van die verskynsel is. 


\section{Verkryging van die proefpersone}

Die kinders is uit hulpklasse van die T.O.D. verkry.

Die proefpersone is spesifiek uit die totale bevolking van hulpklaskinders in Pretoria gekies omdat die brandstofkrisis 'n groter area onmoontlik gemaak het.

Daar bestaan in Pretoria vyftien hulpklasse, elk met 8 leerlinge, met ander woorde, 'n totale bevolking van \pm 120 leerlinge.

'n Verteenwoordigende en ewekansige steekproef van 30 leerlinge tussen die ouderdomme 7-4 tot $9-10$ is uit bg. bevolking getrek.

EKSPERIMENTELE MATERIAAL

Die TMT is gebruik asook

- 'n bandmasjien (draagbare Sony)

- lae-geruis/kasette (Hitachi)

- die ,Samevattende verslag oor 'n leerling met leergestremdhede" (T.O.D. omsendminuut 73 van 1979 - Bylaag A) ${ }^{15}$

Die verslag is deur die betrokke ortodidaktikus wat die hulpklaskinders geselekteer het, voltooi. Daaruit is agtergrond-historiese gegewens vir elke pp ingewin.

PROSEDURE

Die toets is volgens spesifikasies, bv. met betrekking tot omgewing, aanwysings en prosedure afgelê:

\section{STATISTIESE VERWERKING}

Die proefpersone se roupunt vir elkeen van die 16 sub-toetse van die toets is met behulp van die normtabelle na persentielrange omgesit. Laasgenoemde kon egter nie vir statistiese verwerking gebruik word nie en is daarom na staneges verwerk.

Ten einde te bepaal of die pp se prestasie as groep betekenisvol van die normgroep verskil het, is die t-toets vir statisties betekenisvolle verskille op die $5 \%$ en $2 \frac{1}{2} \%$ vlak van betekenisvolheid uitgevoer.

\section{RESULTATE. (sien Tabelle I-III)}

Die resultate word kortliks aan die hand van die spesifieke doelstellings bespreek. Vir 'n meer gedetaileerde bespreking word u verwys na De Koker. 5

\section{Bewys van orale problematiek}

Bewyse het wel deeglik uit die eksperimentele navorsing na vore getree. Die eerste bewys is reeds uit dié leerlinge se agtergrond-gegewens verkry. Daar is gevind dat 'n minimum van $73,3 \%$ van die $p p$ 'n geskiedenis van spraak- en taalverwante probleme gehad het. Daar was bv. by $40 \%$ van die EG spesifiek genoem dat hulle laat begin praat het. Hierdie verskynsel is ook deur Murray ${ }^{12}$ genoem.

Uit Tabel II - blyk dit dat die EG in die TMT op 12 uit die 16 subtoetse betekenisvol swakker as die normale kind presteer het 


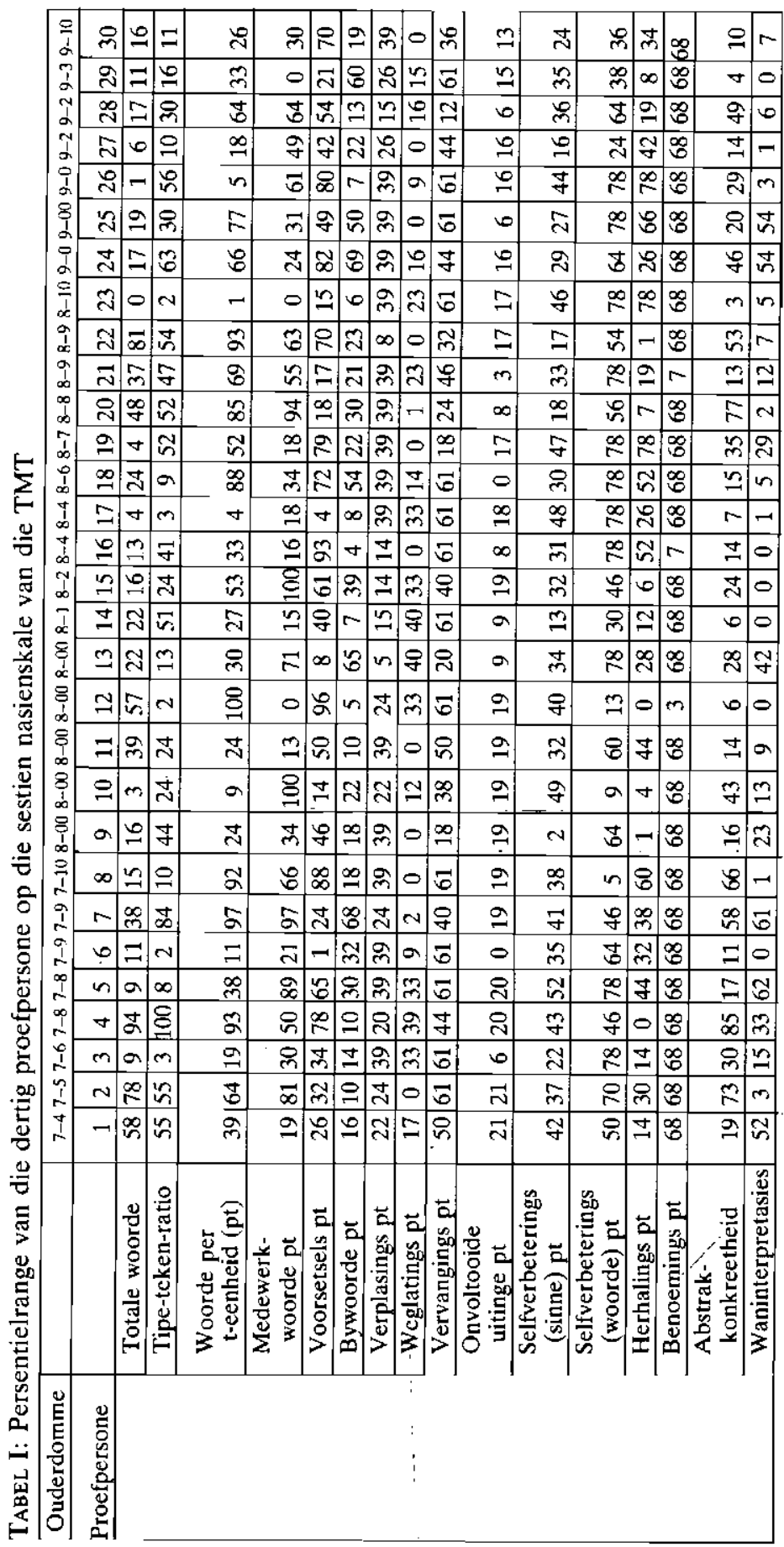

The South African Journal of Communication Disorders, Vol. 28, 1981 
TABEL II: Uitslag van die t-toets vir statistiese betekenisvolheid

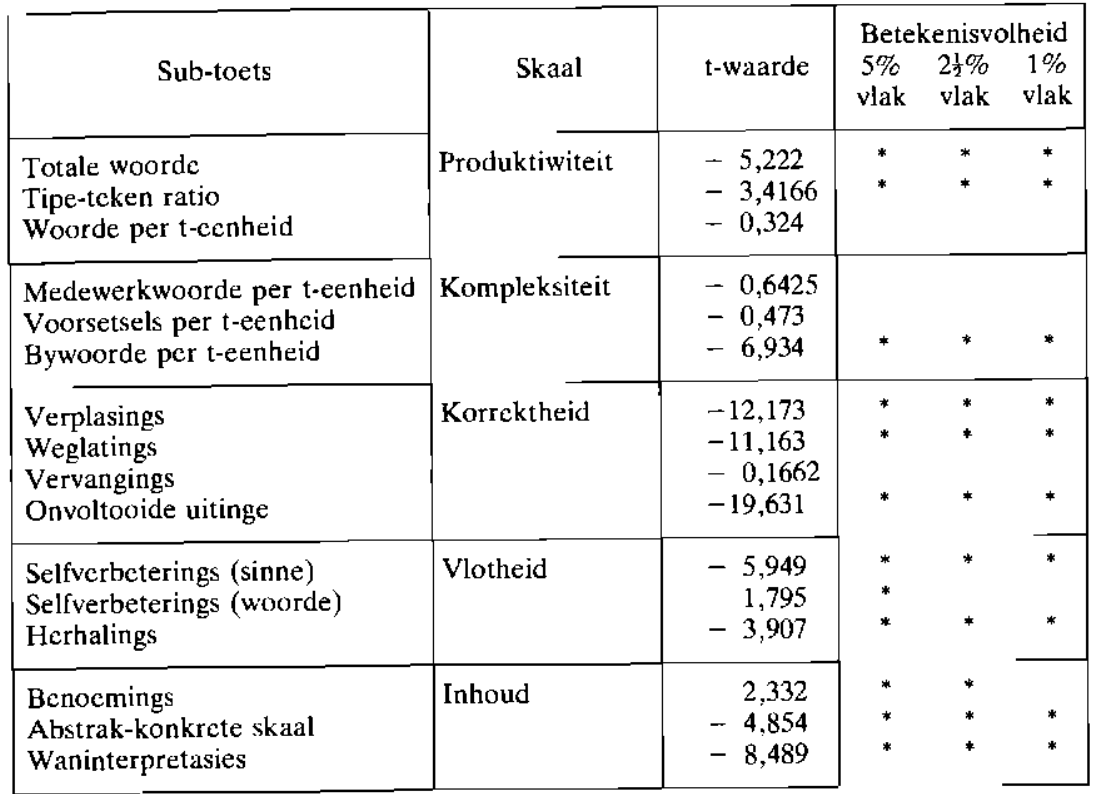

alhoewel hulle gemiddelde en bo-gemiddelde verstandelike vermoëns gehad het.

Die feit dat hierdie kinders, as 'n geweldige heterogene groep tog van die norm-groep afgewyk het, is miskien die grootste bewys van hulle taalprobleme. Verder het dié kinders steeds taalprobleme ondervind ondanks die feit dat hulle reeds vir ' $n$ minimum van nege maande in 'n hulpklas was.

Hierdie wetenskaplike bewyse wat gevind is, dui daarop dat elke persoon wat homself met leergestremde kinders bemoei, van dié kinders se orale taalproblematiek kennis moet dra. Dit is duidelik dat hulp aan die kinders se sekondêre taalprobleme soos lees en skryf van weinig waarde sal wees indien die bousteen $\mathrm{nl}$. orale taal ignoreer word.

\section{Voorkoms van Orale Taalproblematiek}

Leergestremde kinders beskik oor 'n wye variasie van simptome (Wiig en Semel, ${ }^{23}$ ) wat daartoe lei dat hulle moeilik in homogene kategorieë tuishoort. Heterogeniteit by die pp het egter nie tot gevolg gehad dat hulle nie betekenisvol, wat taal betref, van normale kinders verskil het nie.

Daar het 'n geweldig hoë voorkomssyfer van taalprobleme gepresenteer. Indien daar na elke pp se prestasie gekyk word, (Tabel I) is dit opvallend dat elke proefpersoon onder gemiddeld presteer het. Slegs 2 pp het in minder as $50 \%$ van die subtoetse onder-gemiddeld presteer. 
Daar was dus 'n $100 \%$ voorkomssyfer van orale taalproblematiek. Dit is sorgwekkend as daar in ag geneem word dat van die pp amper 10 jaar oud was. Die moontlikheid van taalprobleme tot in die adolessente fase (Wiig en Semel, ${ }^{23}$ ) is met ander woorde nie uitgesluit nie.

Indien daar verder na individuele kinders se prestasie gekyk word (Tabel I) is dit duidelik dat oneweredige prestasie in toetse, soos deur Murray $^{12}$ en Kirk en Kirk ${ }^{10}$ genoem, ook hier voorkom. Ten opsigte van die een subtoets sal een proefpersoon gemiddeld presteer en ten opsigte van die volgende weer onder-gemiddeld. Die geweldige variasie blyk uit die volgende voorbeeld:

TABEL III Persentielrange van proefpersoon 2 op die TMT

\begin{tabular}{|c|c|}
\hline Subtoets & Persentielrang \\
\hline 1 & 78 \\
2 & 55 \\
3 & 64 \\
4 & 81 \\
5 & 32 \\
6 & 10 \\
7 & 24 \\
8 & 0 \\
9 & 61 \\
10 & 21 \\
11 & 37 \\
12 & 70 \\
13 & 30 \\
14 & 68 \\
15 & 73 \\
16 & 3 \\
\hline
\end{tabular}

Die aard van die orale taalproblematiek

Uit die individuele prestasies en groepprestasie volgens die verskillende subtoetse, blyk dit dat daar 'n redelike wye en algemene taalprobleem by die kinders voorgekom het wat nie aan 'n enkele subtoets of taalmodaliteit gebonde was nie. Onderprestasie het by alle subtoetse nl. produktiwiteit, kompleksiteit, korrektheid, vlotheid en inhoud voorgekom. Wiig en Semel ${ }^{23}$ se hipotese dat leergestremde kinders te taalprobleme multi-dimensioneel is, is dus hier onderskryf.

'n Kort opsomming van enkele verdere bevindinge is as volg:-

- Op grond van die EG se prestasie op die produktiwiteitskaal, kan daar afgelei word dat die leergestremde kind se taalgebruik besonder onproduktief is

- verbale perseverasie deur onder andere Green ${ }^{6}$ vermeld het nie by die $E G$ voorgekom nie.

- die EG het ' $n$ minder diverse leksikon vertoon

- Die leergestremde groep se gemiddelde uitingslengte het nie van 
die normale verskil nie. Die lengte van uitinge sou dus nie as 'n waardevolle diagnostiese hulpmiddel by leergestremde kinders aanbeveel word nie.

- Die EG se sinne is deur baie funksielose woorde gekenmerk.

- Wat die prestasie op die kompleksiteitskaal aanbetref, het die EG nie betekenisvol minder medewerkwoorde en voorsetsels as normale kinders gebruik nie. Dit was egter opvallend dat die EG 'n baie hoë frekwensie lokatiewe voorsetsels gebruik het wat volgens Wiig en Semel ${ }^{23}$ baie maklike voorsetsels is

- ondergemiddelde bywoord gebruik het op sintaktiese probleme gedui

- Dit was opvallend dat nie een van die pp besondere komplekse sinne gebruik het nie

- Die EG het meer verplasings, weglatings en onvoltooide uitinge as die normale kind gebruik. Dit skyn dus of die kontrolerende funksie oor hulle spraak nie voldoende is nie

- 'n Verdere bewys vir die foutiewe kontrole oor die taalfunksie is die hoë voorkoms van selfverbeteringe en woordherhalings by dié kinders

- Die leergestremde kind se geweldig baie woordherhalings het die kinders se taal ongetwyfeld in 'n "afasie"-konteks geplaas. Vorster $^{19}$ noem dat die funksielose herhalings van woorde eintlik in die plek van pouses gebruik word waar woordvindingsprobleme ondervind word.

- Uit die EG se uitinge het dit geblyk dat funksielose pouses, tussenwerpsels en herhalings van lettergrepe ook grootliks tot die onvlotheid en onsamehangende taalgebruik bygedra het

- Die EG se taal was besonder konkreet en stimulusgebonde - met ander woorde, verbeeldingloos

- Dié kinders het ook betekenisvol meer waninterpretasies in hulle stories gehad. Dit het dikwels 'n aanduiding gegee van die kinders se gebrekkige logika en onvermoë om 'n storie in die regte perspektief te plaas.

- Oor die algemeen kommunikeer die leergestremde groep swak weens onvlothede, waninterpretasies, konkreet gebondenheid, onlogiese vertellings, tussenwerpsels, foutiewe woordorde en woordherhalings

Indien daar wel vir 'n patroon van taalprobleme by dié kinders gesoek word, skyn dit dat dit EG se grootste probleme in die vlotheid en inhoudsaspekte van orale taal voorgekom het (Tabel III) Wiig en Semel $^{23}$ het die leergestremde kind se onvlotheid ook as een van die belangrikste probleme beskou.

Uit die resultate is dit ook duidelik dat die EG se taalprobleme nie so subtiel is soos vorige navorsers beweer het nie en ook nie so kompleks nie. Alhoewel die probleme wel kompleks mag wees is daar sprake van redelike eenvoudige en basiese probleme soos bv. onderbeklemtoning van die gebruik van bywoorde. 
Daar is ten slotte in hierdie navorsing slegs op ekspressiewe orale taal gekonsentreer. Omdat resepsie ekspressiewe voorafgaan, is dit dus nie onrealisties om te vermoed dat leergestremde kinders ook reseptiewe orale taalprobleme ondervind nie.

\section{Nut van die TMT}

Uit hierdie navorsing het dit geblyk dat die TMT 'n nuttige instrument is, en wel in die volgende opsig:

- Hierdie toets meet kinders se taakvermoë oor 'n wye verskeidenheid van afdelings en nie net op die sintaktiese gebied nie. Crystal et al $^{4}$ laat bv. aspekte soos vlotheid en inhoud (juis hierdie kinders se grootste probleem) agterweë

- Die afneem van die toets geskied oor 'n baie kort tydsbestek wat dit baie bruikbaar by veral hiperaktiewe kinders maak.

- Die TMT verskaf normatiewe data aan die hand waarvan Afrikaanse kinders se taal evalueer kan word. (Ook vir die ouer kind) As gevolg van die aard van die toets is daar egter ook nadele aan verbonde:

- Die toets is op grond van die kwantitatiewe aard daarvan onderhewig aan kritiek aldus Bloom en Lahey. ${ }^{3}$ Menslike gedrag is aldus die outeurs nie tot syfers reduseerbaar nie. Die toets gee verder nie omvattende riglyne vir terapie nie. Dit is wel die geval wanneer taalmonsters kwalitatief ontleed word.

- Die EG, en dan veral ouer kinders, se sintaktiese ontwikkeling word te oppervlakkig beoordeel.

- Die morfologiese aspek van taal word nie geëvalueer nie, net so ook nie die funksies van taal- en kommunikasievermoëns nie.

- Die toets word visueel aangebied, 'n faktor wat by leergestremde kinders, weens hulle perseptuele defekte, moontlik die kwaliteit van die taalmonster verlaag.

- Die insluiting van pouses, tussenwerpsels en herhalings van klanke sou die vlotheidskaal meer bruikbaar gemaak het. (Dit het wel deeglik tot die EG se onvlotheid bygedra).

\section{KONKLUSIE}

Uit die voorafgaande bespreking het dit duidelik geword dat die leergestremde kind probleme met gesproke taal onderyind wat, ondanks remediëring en normale verstandelike vermoënś, selfs op nege-jarige ouderdom nog voorkom.

Dit is egter nie duidelik wat die oorsaak van die leer- en taalprobleem is nie en ook welke verband daar tussen hierdie twee probleemsituasies heers nie. Daar bestaan ook nog onduidelikheid oor die wyse waarop die kinders se taalsimptome verklaar kan word.

'n Verdere twispunt is die vraag of 'die kinders se taal kwalitatief of kwantitatief van die normale verskil.' Wiig. en Semel $^{23}$ het gevind dat leergestremde kinders se sintaksis afwykend maar ook vertraag is. 
Uit die eksperimentele navorsing is daar beperkte bewyse ter ondersteuning van beide gevind.

Ten opsigte van kwalitatiewe verskille kan gesê word dat die kinders se taal in 'n "afasie-konteks" geplaas is met die bewyse van hulle woordvindingsprobleme en waninterpretasies.

Dit blyk egter nie moontlik te wees om leergestremde kinders se simptome met volwasse afate se simptome te korreleer nie, aangesien eersgenoemde se simptome nie so ekstensief is nie en daar ook nie van verworwe breinletsels by dié kinders sprake is nie. Tog wil dit voorkom of daar 'n merkbare ooreenkoms tussen leergestremde kinders en kinderafate kan wees.

Resente definisies van kinderafasie deur onder andere Jakobson, ${ }^{8}$ waar afasie na probleme in begrip en gebruik van linguistiese simbole verwys, kan direk op leergestremde kinders van toepassing gemaak word.

Verskeie navorsers het al hierdie noue ooreenkoms tussen afatiese en leergestremde kinders ingesien. Abrahams ${ }^{1}$ noem die volgende:

it seems that the language disordered child could be said to fall into the wider syndrome of the so-called $M B D$ children

Hallahan en Kauffman ${ }^{7}$ sê dat Eisenson van mening is dat die leergestremde en afatiese kind een en dieselfde persoon is. Pelzer ${ }^{14}$ verklaar die skynbare verband as volg: "afasie is voor disleksie sigbaar" met ander woorde, die een verskynsel gaan die ander slegs vooraf.

Die vraag wat dus in die toekoms beantwoord moet word, is die volgende: In welke mate ontstaan leerprobleme uit 'n basiese taalonvermoë?

\section{VERWYSINGS}

1. Abrahams, E. A., (1972): Follow-up Study of Children with a History of Language Disorders. Ongepubliseerde tesis, Universiteit van Witwatersrand.

2. Baren, M., et al, (1978): Overcoming Learning Disabilities. A Team Approach. Reston Publishing Company, Virginia.

3. Bloom, L. en Lahey, M., (1978): Language Development and Language Disorders. John Wiley and Sons, New York.

4. Crystal, D. et al, (1976): The Grammatical Analysis of Language Disability. Edward Arnold Publishers, London.

5. De Koker, E., (1980): 'n Ondersoek na Taalprobleme by leergestremde kinders. Ongepubliseerde Magister Tesis, Universiteit van Pretoria.

6. Green, G., (1974): Kommunikasieprobleme by Psigoneurologiese Disfunksie. Ongepubliseerde tesis, Universiteit van Pretoria.

7. Hallahan, D. P. en Kauffman, J. M. (1976): Introduction to Learning Disabilities. A Psycho-behavioral Approach. Prentice Hall, Inc., Englewood Cliffs, New Jersey. 
8. Jakobson, R., (1971): Studies on Child Language and Aphasia. Mouton, The Hague.

9. Johnson, D. J. en Myklebust, H. R., (1967): Learning Disabilities. Educational Principles and Practices. Grune and Stratton, New York.

10. Kirk, S. A... en Kirk, W. D., (1976): Psycholinguistic Learning Disabilities. Diagnosis and Remediation. University of Illinois Press, Illinios.

11. Moran, M. R. en Byrne, M. C., (1977): Mastery of Verb Tense Markers by Normal and Learning Disabled children, J.S.H.R., 20, (3) p. 529.

12. Murray, C. H. de C., (1969): Verslag van die Komitee van Ondersoek na die Opvoeding van Kinders met Minimale Breindisfunksie. (R/P. 72/1969) Staatsdrukker, Pretoria.

13. Myers, P. I. en Hammill, D. D., (1976): Methods for Learning Disorders. John Wiley and sons, Inc. New York.

14. Pelzer, W., (1965): Spraakterapeutiese benadering tot Kinderafasie. Universiteit van Pretoria. Ongepubliseerde tesis.

15. Samevattende Verslag oor ' $n$ leerling met leergeremdhede. T.O.D. Omsendminuut 73 van 1979. Bylaag A.

16. Schain, R. J., (1972): Neurology of Childhood Learning Disorders. Williams \& Wilkins, Baltimore.

17. Uys, I. C., (1974): Psigoneurologiese disfunksie: 'n Tipering volgens sekere spraakpatologiese verskynsels. Ongepubliseerde tesis, Universiteit van Pretoria.

18. Vogel, S. A., (1977): Morphological Ability in Normal and Dyslexic Children. Journal of Learning Disabilities, 10, (1), p. 41

19. Vorster, J., (1980): Handleiding vir die Toets vir Mondelingse Taalproduksie. Raad vir Geesteswetenskaplike Navorsing, Pretoria.

20. Wallach, G. P. en Goldsmith, S. C., (1977): Language Based Learning Disabilities: Reading is Language too! Journal of Learning Disabilities, Vol. 10, p. 178.

21. Wiig, E. H. en Roach, M. A., (1975): Immediate Recall of Semantically varied Sentences by Learning Disabled Adolescents. Perceptual + Motor Skills. Vol. 40, p. 119.

22. Wiig, E. H. en Semel, E. M., (1973): Comprehension of Linguistic Concepts requiring Logical Operations, J.S.H.R. Vol. 16, p. 627.

23. Wiig, E. H. en Semel, E. M., (1976): Language Disabilities in Children and Adolescents. Charles E. Merrill, Ohio. 


\section{IN-SITU MEASUREMENT OF HEARING AID GAIN}

1. Acoustimed has developed a measuring system for testing the insertion gain (Etymotic Response) of hearing aids in real ears with the earmould in position.

2. To the best of our knowledge there are only three similar systems in use in the world and the Acoustimed instrument is the only one which prevents artifacts from standing waves and noise generated in the room, e.g. the subject's own voice.

3. The system is presently in use for routine fitting of hearing aids and to improve understanding of the problems encountered in the fitting of hearing aids.

4. Audiologists and universities are invited to make use of the system to assist patients at no charge.

\section{ACOUSTIMED HEARING SERVICES 315 BOSMAN BUILDINGS COR. ELOFF AND BREE STREETS JOHANNESBURG \\ TEL: 37-2977}

Agents for Daク HEARING AIDS 